\title{
PENGARUH PERENDAMAN FILLER SERAT AMPAS TEBU DENGAN VARIASI KONSENTRASI NaOH TERHADAP SIFAT MEKANIK KOMPOSIT RESIN POLYESTER
}

\author{
Wike Wiranda dan M.H.Harahap *
}

Jurusan Fisika, Fakultas Matematika dan Ilmu Pengetahuan Alam, Universitas Negeri Medan, Indonesia

\begin{abstract}
Abstrak
Penelitian ini bertujuan untuk mengetahui pengaruh perendaman serat dengan menggunakan $\mathrm{NaOH}$ serta model serat searah dan acak terhadap kekuatan tarik, kekuatan lentur, kekuatan impak dari komposit serat ampas tebu dengan menggunakan resin polyester. Dalam penelitian ini, dibuat komposit serat ampas tebu dengan perendaman $0 \%, 3 \%, 5 \%$ dan $7 \% \mathrm{NaOH}$ dengan penyusunan serat ampas tebu model searah dan acak dan diikat dengan resin polyester. Prosedur dari penelitian ini adalah mengeringkan ampas tebu agar dapat diambil seratnya. Setelah itu serat ampas tebu direndam dengan variasi perendaman $0 \%, 3 \%, 5 \%$, $7 \%$. Lalu serat yang telah direndam selama 1 jam dikeringkan kembali, untuk disusun dalam cetakan dengan model searah dan acak kemudian dicampur dengan resin polyester menjadi komposit. Kemudian komposit dipress menggunakan hot press dengan suhu $120^{\circ} \mathrm{C}$ selama $\pm 30-35$ menit. Setelah itu komposit dipotong-potong sesuai ukuran uji kekuatan mekanik yaitu meliputi pengujian kekuatan tarik, kekuatan lentur, dan kekuatan impak. Hasil penelitian menunjukkan komposit serat ampas tebu dengan model searah untuk perendaman $0 \%, 3 \%, 5 \%$, dan 7\% diperoleh kekuatan tarik masing masing sebesar 3,05 $\mathrm{N} / \mathrm{mm}^{2}, 11,04 \mathrm{~N} / \mathrm{mm}^{2}, 16,51 \mathrm{~N} / \mathrm{mm}^{2}$, dan $16,08 \mathrm{~N} / \mathrm{mm}^{2}$. Untuk model acak diperoleh kekuatan tarik sebesar $5,03 \mathrm{~N} / \mathrm{mm}^{2}, 13,12 \mathrm{~N} / \mathrm{mm}^{2}, 11,13 \mathrm{~N} / \mathrm{mm}^{2}$, dan 10,79 N/mm². Untuk kekuatan lentur komposit serat ampas tebu model searah diperoleh kekuatan lentur masing-masing sebesar 6,7 MPa, 7,1 MPa, 9,8 $\mathrm{MPa}$, dan 32,1 MPa. Sedangkan untuk serat model acak diperoleh kekuatan lentur sebesar 2,5 MPa, 4,8 MPa, 9,6 MPa, 27,4 MPa. Untuk kekuatan impak serat ampas tebu model searah diperoleh kekuatan impak sebesar $4247,2 \mathrm{~J} / \mathrm{m}^{2}, 5468,3 \mathrm{~J} / \mathrm{m}^{2}, 2821,7 \mathrm{~J} / \mathrm{m}^{2}$, dan $2207,6 \mathrm{~J} / \mathrm{m}^{2}$. Sedangkan pada serat model acak diperoleh kekuatan impak sebesar 2700,6 J/m², $3831 \mathrm{~J} / \mathrm{m}^{2}, 1891,1 \mathrm{~J} / \mathrm{m}^{2}$, dan 1336,9 J/mm². Dari hasil penelitian menunjukkan bahwa perendaman dengan menggunakan $\mathrm{NaOH}$ dan model serat searah dapat meningkatkan kekuatan mekanik komposit serat ampas tebu.
\end{abstract}

Kata Kunci : Polyester, NaOH, Ampas Tebu, Serat Acak, Serat Searah.

How to Cite: Wike Wiranda dan M.H.Harahap, (2015), Pengaruh Perendaman Filler Serat Ampas Tebu Dengan Variasi Konsentrasi Naoh Terhadap Sifat Mekanik Komposit Resin Polyester, Jurnal Einsten Prodi Fisika FMIPA Unimed, 3 (2): 31-37.

*Corresponding author:

E-mail :wirandawike@gmail.com

p-ISSN : I2338 - 1981 


\section{PENDAHULUAN}

Proses pengambilan serat ampas tebu dilakukan dengan cara memilih serat ampas tebu yang telah bersih dari kotoran dan tanah dibersihkan dan dikeringkan. Serat ampas tebu direndam satu hari lalu dicuci bersih untuk menghilangkan rasa manis dari serat, kemudian disisir dengan sikat kawat untuk menghilangkan gabus yang menempel dengan serat. Serat ampas tebu yang telah dibersihkan kemudian dikeringkan dibawah sinar matahari sampai benar-benar kering selama \pm 7 hari.

Serat ampas tebu yang telah dikeringkan dilakukan penyisiran lagi untuk menghilangkan gabus yang masih melekat pada serat. Kemudian memotong serat dengan panjang $50 \mathrm{~mm}$ dan $20 \mathrm{~mm}$ dengan menggunakan gunting dan merendam serat ampas tebu dengan larutan $\mathrm{NaOH} 3 \%, 5 \%, 7$ $\%$ selama 1 jam. Setelah perendaman serat ampas tebu dibersihkan dengan aquades. Kemudian serat dikeringkan dengan cara diangin-anginkan sampai serat benar-benar kering. Kemudian meletakkan spacer dikeempat sudut alas cetakan yang berukuran $25 \times 25 \mathrm{~cm}$ yang bertujuan untuk menentukan ketebalan komposit $4 \mathrm{~mm}$ Pencampuran resin polyester dengan katalis untuk membantu proses pengeringan. Katalis yang digunakan 1\% dari banyaknya resin yang digunakan. Penuangan sebagian campuran resin polyester ke dalam cetakan, kemudian dilanjutkan dengan penempatan serat secara searah dengan panjang serat $5 \mathrm{~cm}$ untuk orientasi serat searah dan untuk serat secara acak mencampur resin polyester dengan katalis kemudian diaduk sampai rata dan dicampur dengan serat ampas tebu dengan panjang $2 \mathrm{~cm}$ untuk orientasi serat acak, kemudian ditekan dengan roller.

Serat yang sudah dicampur resin pada cetakan dipukul-pukul menggunakan sendok agar campuran resin masuk ke dalam serat dan kemudian ditekan dengan roller. Kemudian serat ditutup dengan tujuan agar void yang tampak dapat diminimalkan, kemudian dilakukan pengepresan dengan alat pengepres. Pengeringan dilakukan sampai komposit benarbenar kering yaitu 6-10 jam dan apabila belum kering maka proses pengeringan dapat dilakukan lebih lama. Komposit yang telah kering diambil dari cetakan menggunakan pisau ataupun cutter. Komposit kemudian dipotong menjadi spesimen benda uji. Pengujian tarik dan lentur dilakukan terhadap specimen/batang uji dengan menggunakan Universal Testing Machine (UTM). Pengujian tarik dilakukan sampai specimen/batang uji putus. Pada saat pengujian gaya atau tegangan dan perubahan panjang batang atau regangan di monitoring dan disajikan dalam kurva tegangan-regangan. Sementara untuk pengujian impak posisi spesimen uji pada tumpuan dengan posisi horizontal/ mendatar, dan arah pembebanan berlawanan dengan arah takikan. Kemudian mengangangkat beban alat uji keatas dan kemudian melepaskan beban dengan menumbuk sampel. Data akan terlihat pada alat dengan melihat jarum penunjuk nya.

Bentuk spesimen pengujian kekuatan tarik dengan menggunakan ASTM D 638 dapat dilihat pada gambar 1.1. di bawah ini :

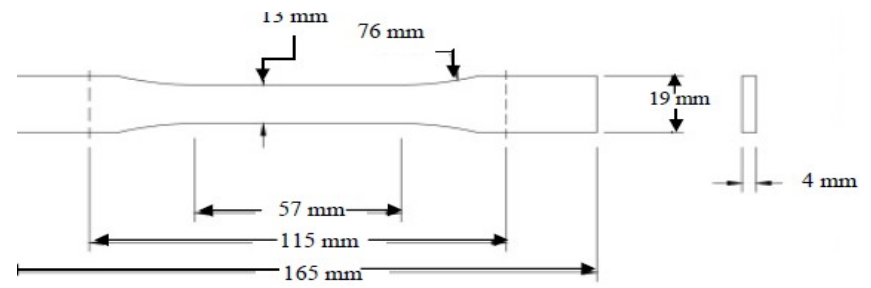

Gambar 1. Spesimen Uji Tarik ASTM D 638

Bentuk spesimen pengujian lentur dan impak menggunakan ASTM D 790, dapat dilihat pada gambar 2.2. di bawah ini

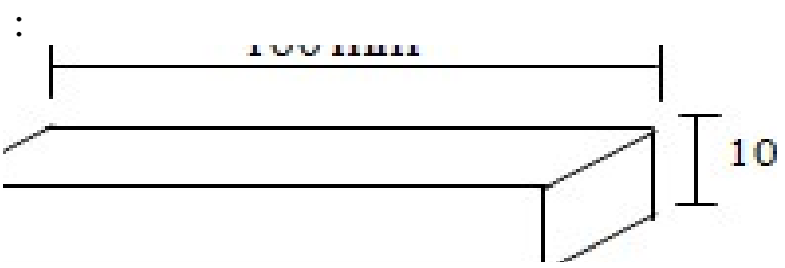

Gambar 2. Spesimen Uji Lentur dan Impak ASTM D 790

\section{HASIL DAN PEMBAHASAN Pengujian Kekuatan Tarik}

Pengujian tarik (tensile test) adalah pengujian mekanik secara statis dengan cara sample ditarik dengan pembebanan pada kedua ujungnya dimana gaya tarik yang diberikan sebesar $\mathrm{P}$ (Newton). Tujuannya untuk mengetahui sifat-sifat mekanik tarik (kekuatan tarik) dari komposit yang diuji diperkuat dengan serat kelapa. Pertambahan panjangan $(\Delta l)$ yang terjadi akibat kakas tarikan yang diberikan pada sampel uji disebut deformasi.

Tabel 1. Data Hasil Pengujian Kekuatan Tarik 


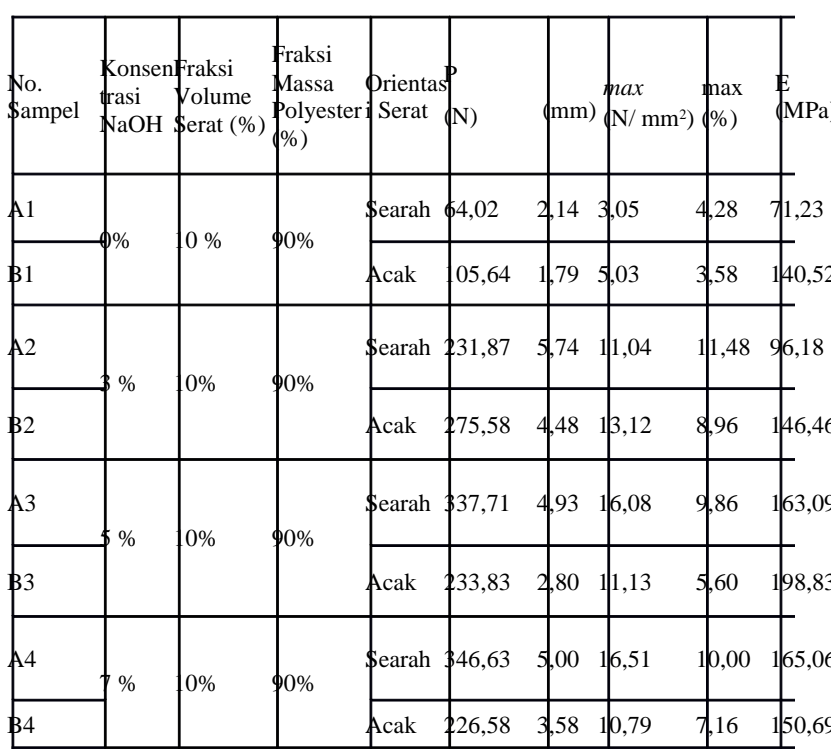

Dari tabel 1. diperoleh grafik hubungan antara pengaruh konsentrasi $\mathrm{NaOH}$ pada perendaman filler serat ampas tebu terhadap kekuatan tarik komposit seperti gambar dibawah ini.

Gambar 3. Grafik hubungan kekuatan tarik maksimum komposit serat ampas tebu dan konsentrasi $\mathrm{NaOH}$

Dari gambar 3. didapatkan bahwa kekuatan tarik tertinggi adalah pada komposit orientasi serat searah dengan (perendaman serat dengan $\mathrm{NaOH} \mathrm{5 \% )yaitu}$ sebesar dan kekuatan tarik terendah adalah pada komposit serat searah dengan (perendaman $\mathrm{NaOH} \mathrm{0 \% )} \mathrm{yaitu} \mathrm{sebesar} \mathrm{.}$ Kekuatan ini dipengaruhi oleh penambahan persentase $\mathrm{NaOH}$ sampai batas optimum yaitu $5 \% \mathrm{NaOH}$ yang dapat meningkatkan kekuatan tarik. Komposit yang diberi perlakuan 5\% $\mathrm{NaOH}$, kekuatannya masih lebih tinggi dibandingkan dengan komposit serat ampas tebu dengan persentase $3 \% \mathrm{NaOH}$ dan $7 \% \mathrm{NaOH}$ maupun dengan tanpa perendaman $\mathrm{NaOH}$. Pada komposit yang diperkuat dengan serat tanpa perendaman $\mathrm{NaOH}$, maka ikatan antara serat dan resin menjadi tidak sempurna karena terhalang oleh adanya lapisan yang menyerupai lilin di permukaan serat, sehingga ketika diuji tarik kegagalan di dominasi oleh lepasnya ikatan antara serat dengan matrik yang diakibatkan oleh tegangan geser di permukaan serat yang disebut dengan istilah fiber pull out. Pada komposit yang diperkuat serat dengan perendaman $\mathrm{NaOH}$ $7 \%$ untuk serat searah dan acak memiliki kekuatan tarik masing-masing dan , ternyata kekuatan tariknya menurun dibandingkan perendaman serat dengan $\mathrm{NaOH} 5 \%$.

Hal ini disebabkan pada perendaman dengan $\mathrm{NaOH} \quad 7 \%$ heniselulosa, lignin dan pektin hilang sama sekali maka kekuatan serat alam akan menurun karena kumpulan microfibril penyusun serat yang disatukan oleh lignin dan pectin akan terpisah, sehingga serat hanya berupa serat-serat halus yang terpisah satu sama lain.

Hal ini menunjukkan adanya pengaruh konsentrasi $\mathrm{NaOH}$ pada kekuatan tarik maksimum. Jika konsentrasi larutan terlalu tinggi akan merusak sel-sel serat utamanya sehingga serat menjadi rapuh, keropos, dan kekuatannya berkurang. Dari gambar juga diperoleh kekuatan tarik maksimum dipengaruhi oleh orientasi serat, dari grafik kekuatan tarik maksimum ada pada orientasi serat searah (perendaman $\mathrm{NaOH} 5 \%$ ) karena secara teori serat searah dapat menyalurkan pembebanan atau tegangan dari satu titik ke titik lainnya sehingga ketika komposit diberikan gaya tarik maka matriks akan dapat menahan gaya tersebut dan diteruskan oleh serat sebelum akhirnya komposit tersebut akan putus/patah. Pada penelitian sebelumnya (Dian Cipta, 2010) perendaman serat ampas tebu dengan menggunakan boraks $0 \%$, 5\%, dan $10 \%$ diperoleh kekuatan tarik maksimum komposit masing-masing sebesar 9,45 $\mathrm{MPa}, 11,89 \mathrm{MPa}, 5,55 \mathrm{MPa}$. Sedangkan hasil penelitian disini diperoleh kekuatan tarik yang lebih baik yaitu sebesar pada perendaman serat dengan $\mathrm{NaOH} 5 \%$.

Dari tabel 1. diperoleh grafik hubungan antara pengaruh konsentrasi $\mathrm{NaOH}$ pada 
perendaman serat ampas tebu terhadap regangan komposit seperti gambar dibawah ini.

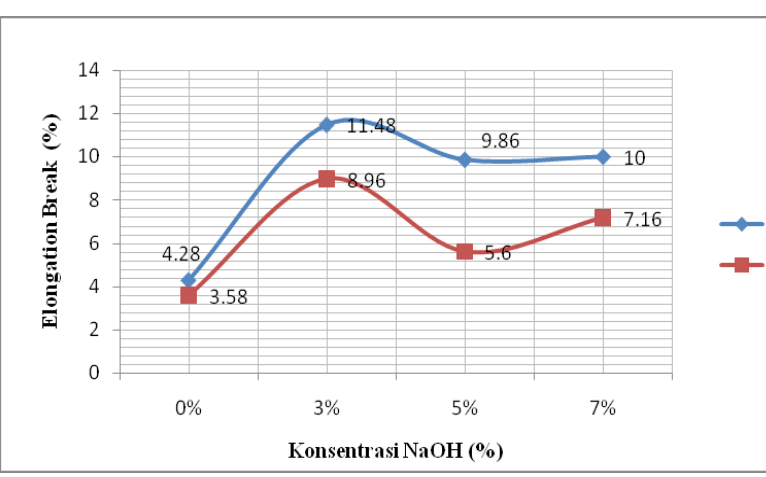

Gambar 4. Grafik regangan maksimum komposit serat ampas tebu dan konsentrasi $\mathrm{NaOH}$

Dari gambar 4. didapatkan regangan maksimum tertinggi adalah pada komposit orientasi serat acak dengan (perendaman serat dengan $\mathrm{NaOH} \mathrm{3 \% )} \mathrm{yaitu}$ sebesar $=11,48 \%$ dan regangan tarik terendah adalah pada komposit serat acak dengan (perendaman $\mathrm{NaOH} \mathrm{0 \%}$ atau tanpa perendaman) yaitu sebesar $=3,58 \%$. Pada komposit yang diperkuat serat tanpa perendaman $\mathrm{NaOH}$ diperoleh regangan terendah dimana ikatan antara serat dan matrik tidak sempurna karena terhalang oleh adanya lapisan yang menyerupai lilin dipermukaan serat, sehingga ketika diuji tarik kegagalan didominasi oleh lepasnya ikatan antara serat dengan matrik. Pada kondisi kegagalan ini, matrik dan serat sebenarnya masih mampu menahan beban dan meregang yang lebih besar, tetapi karena ikatan antara serat dan matrik gagal maka komposit pun mengalami kegagalan lebih awal. Besarnya regangan dan tegangan ketika gagal juga menjadi lebih rendah.

\section{Pengujian Kekuatan Lentur}

Pada pengujian kekuatan lentur dimaksudkan untuk mengetahui ketahanan komposit terhadap pembebanan dan juga untuk mengetahui keelastisan suatu bahan.
Tabel 2. Data hasil pengujian kekuatan lentur

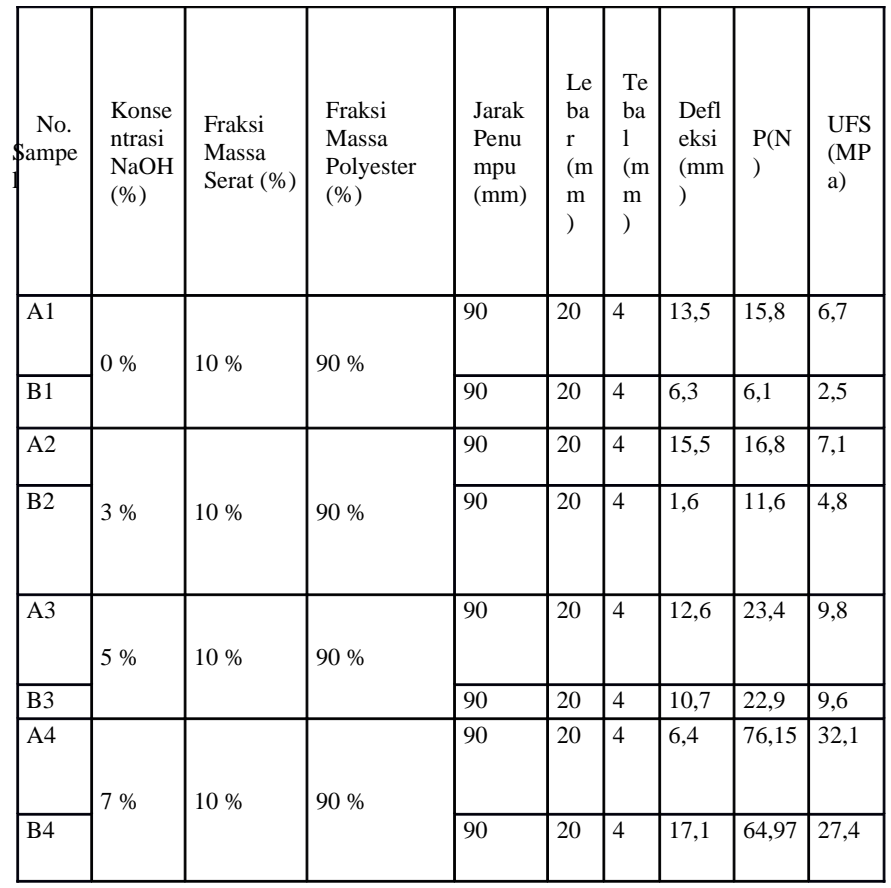

Dari tabel 2. maka dapat dibuat grafik hubungan antara pengaruh konsentrasi $\mathrm{NaOH}$ pada perendaman filler serat ampas tebu terhadap kekuatan lentur komposit seperti gambar dibawah ini.

Gambar 5. Grafik kekuatan lentur maksimum komposit serat ampas tebu dan konsentrasi $\mathrm{NaOH}$

Dari gambar 5. menunjukkan bahwa kekuatan lentur tertinggi adalah pada komposit orientasi serat searah dengan (perendaman serat dengan $\mathrm{NaOH}$ $7 \%$ ) yaitu sebesar UFS $=32,1 \mathrm{MPa}$ dan kekuatan lentur terendah adalah pada komposit serat acak dengan (perendaman $\mathrm{NaOH} 0 \%$ atau tanpa perendaman) yaitu sebesar UFS = 2,5 MPa.Dalam penelitian ini, kekuatan lentur juga meningkat dengan perlakuan alkali. Hasil penelitian menunjukkan peningkatan kekuatan lentur dengan perendaman $\mathrm{NaOH}$ hal ini disebabkan karena pengaruh pelakuan kimia pada serat juga dapat membersihkan dan mengubah topografi permukaan serat, meningkatkan kekerasan permukaan serat sehingga dapat meningkatkan daya ikat 
interfacial antara serat ampas tebu dengan matriks. Kekuatan lentur pada komposit tergantung pada daya rekat antara penguat dan matriknya. Semakin besar kekuatan lentur komposit, maka energi yang diperlukan untuk melepas ikatan serat dengan matriknya semakin besar. Pada grafik juga diperoleh kekuatan lentur terendah ada pada komposit serat acak, hal ini dipengaruhi oleh perletakan serat yang acak di dalam komposit tidak teratur sehingga orientasi serat yang acak tidak mampu secara optimum menahan gaya yang diberikan pada arah dimana gaya bekerja. Pada penelitian sebelumnya (Sijabat Repina 2009) perendaman serat tandan kosong kelapa sawit dengan menggunakan $\mathrm{NaOH} 5 \%, 10 \%$, dan $15 \%$ diperoleh kekuatan lentur maksimum komposit masing-masing sebesar 1,003 MPa, 1,173 MPa, 2,482 MPa. Sedangkan hasil penelitian disini diperoleh kekuatan lentur yang jauh lebih baik yaitu sebesar pada perendaman serat dengan $\mathrm{NaOH} 7 \%$.

\section{Pengujian Kekuatan Impak}

Pengujian impak bertujuan mengetahui ketangguhan suatu bahan terhadap pembebanan dinamis, sehingga dapat diketahui apakah suatu bahan yang diuji rapuh atau kuat.

Tabel 3. Data Hasil Pengujian Kekuatan Impak

\begin{tabular}{|c|c|c|c|c|c|c|c|c|}
\hline $\begin{array}{l}\text { No. } \\
\text { Samp } \\
\text { el }\end{array}$ & $\begin{array}{l}\text { Konsent } \\
\text { asi } \\
\mathrm{NaOH} \\
(\%)\end{array}$ & $\begin{array}{l}\text { Fraksi } \\
\text { Massa } \\
\text { Serat (\%) }\end{array}$ & $\begin{array}{l}\text { Fraksi } \\
\text { Massa } \\
\text { Polyest } \\
\mathrm{r} \\
(\%)\end{array}$ & $\begin{array}{l}\text { Orientasi } \\
\text { Serat }\end{array}$ & $\begin{array}{l}\text { Lebar } \\
\text { (m) }\end{array}$ & $\begin{array}{l}\text { Tebal } \\
(\mathrm{m})\end{array}$ & $\mathrm{A}^{\circ}\left(\mathrm{m}^{2}\right)$ & $\mathrm{E}_{\mathrm{s}}(\mathrm{J}$ \\
\hline$\overline{\mathrm{A} 1}$ & \multirow{2}{*}{$0 \%$} & \multirow{2}{*}{$10 \%$} & \multirow{2}{*}{$90 \%$} & Searah & 0,02 & 0,004 & & $\overline{0,34} 4$ \\
\hline B1 & & & & Acak & 0,02 & 0,004 & & 0,22 \\
\hline $\mathrm{A} 2$ & \multirow{2}{*}{$3 \%$} & \multirow{2}{*}{$10 \%$} & \multirow{2}{*}{$90 \%$} & Searah & 0,02 & 0,004 & & $\overline{0,4} 4$ \\
\hline B2 & & & & Acak & 0,02 & 0,004 & & $\overline{0,3} 1$ \\
\hline $\mathrm{A} 3$ & \multirow{2}{*}{$5 \%$} & \multirow{2}{*}{$10 \%$} & \multirow{2}{*}{$90 \%$} & Searah & 0,02 & 0,004 & & $\overline{0,23}$ \\
\hline B3 & & & & Acak & 0,02 & 0,004 & & $\overline{0,15}$ \\
\hline $\mathrm{A} 4$ & \multirow{2}{*}{$7 \%$} & \multirow{2}{*}{$10 \%$} & \multirow{2}{*}{$90 \%$} & Searah & 0,02 & 0,004 & & $\overline{0,18}$ \\
\hline B4 & & & & Acak & 0,02 & 0,004 & & $\overline{0,11}$ \\
\hline
\end{tabular}

Dari tabel 3. maka dapat dibuat grafik hubungan antara pengaruh konsentrasi $\mathrm{NaOH}$ pada perendaman filler serat ampas tebu terhadap kekuatan impak komposit seperti gambar dibawah ini.

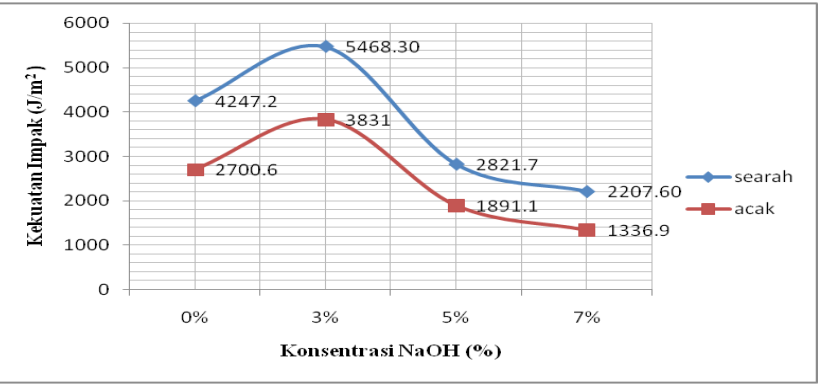

Gambar 6. Grafik kekuatan impak komposit serat ampas tebu dan konsentrasi $\mathrm{NaOH}$

Dari gambar 6. menunjukkan bahwa kekuatan impak tertinggi adalah pada komposit orientasi serat searah dengan (perendaman serat dengan $\mathrm{NaOH}$ $3 \%$ ) yaitu sebesar $=5468,3 \mathrm{~J} / \mathrm{m}^{2}$ dan kekuatan impak terendah adalah pada komposit serat acak dengan (perendaman $\mathrm{NaOH} 0 \%$ atau tanpa perendaman) yaitu sebesar $=1336,9 \mathrm{~J} / \mathrm{m}^{2}$. Data penelitian menunjukkan terjadinya penurunan kekuatan impak pada perendaman dengan konsentrasi $\mathrm{NaOH}$ yang lebih tinggi, dimana larutan dengan konsentrasi yang lebih tinggi akan merusak sel- sel serat utamanya/ degradasi kimiapada serat sehingga serat menjadi rapuh dan kekuatannya berkurang. Dari grafik juga diperoleh kekuatan impak terendah ada pada komposit serat acak hal ini disebabkan oleh distribusi serat yang kurang merata sehingga sifat mekanik pada satu arahnya akan semakin melemah sementara pada serat searah didapatkan kekuatan impak tertinggi hal ini dipengaruhi oleh perletakan serat yang searah di dalam komposit sehingga orientasi serat dalam komposit teratur. Sehingga ketika komposit diberikan gaya maka matriks akan dapat menahan gaya tersebut dan diteruskan oleh serat sebelum akhirnya komposit tersebut akan putus. Pada penelitian sebelumnya mengenai " Pengaruh Konsentrasi Bahan Pengawet Boraks terhadap Serat Tebu Sebagai Bahan Komposit", yang dilakuakan oleh Wita Armaya diperoleh kekuatan impak ratarata untuk konsentrasi boraks $0 \%, 5 \%$, $10 \%$, dan $15 \%$ masing-masing sebesar $3447 \mathrm{~J} / \mathrm{m}^{2}, 3589 \mathrm{~J} / \mathrm{m}^{2}, 5384 \mathrm{~J} / \mathrm{m}^{2}$, dan 7691 
$\mathrm{J} / \mathrm{m}^{2}$. Pada peneltian disini kekuatan impak tertinggi diperoleh pada perendaman serat dengan $\mathrm{NaOH} 3 \%$ sebesar $=5468,3 \mathrm{~J} / \mathrm{m}^{2}$, hasil ini menunjukan kekuatan tarik mendekati hasil maksimum pada penelitian sebelumnya.

Dari tabel 3. diperoleh hubungan antara pengaruh konsentrasi $\mathrm{NaOH}$ pada perendaman filler serat ampas tebu terhadap energi serap komposit seperti gambar dibawah ini.

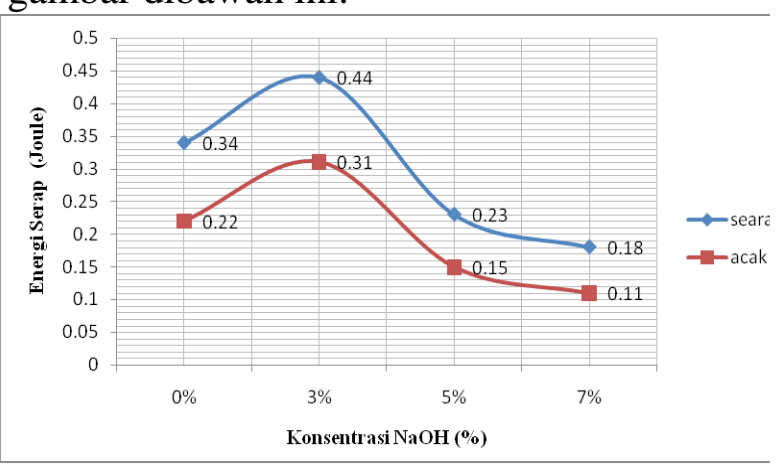

Gambar 7. Grafik energi serap komposit serat ampas tebu dan konsentrasi $\mathrm{NaOH}$

Dari gambar 7. menunjukkan bahwa energi serap tertinggi adalah pada komposit orientasi serat searah dengan (perendaman serat dengan $\mathrm{NaOH} 3 \%$ ) yaitu sebesar $=0,44$ Joule dan energi serap terendah adalah pada komposit serat acak dengan (perendaman $\mathrm{NaOH} 7 \%$ ) yaitu sebesar $=0,11$ Joule. Menurut Kuncoro Diharjo (2006) pada komposit yang diperkuat dengan serat tanpa perlakuan, maka ikatan (mechanical bonding) antara serat dan matriks menjadi tidak sempurna karena terhalang oleh lapisan yang menyerupai lilin dipermukaan serat. Perlakuan $\mathrm{NaOH}$ ini bertujuan untuk melarutkan lapisan yang menyerupai lilin di permukaan serat seperti lignin, hemiselulosa, dan kotoran lainnya. Dengan hilangnya lapisan lilin ini maka ikatan antara serat dan matrik menjadi lebih kuat, sehingga kekuatan mekanik komposit menjadi lebih kuat.

\section{KESIMPULAN}

Berdasarkan data hasil pengujian dan pembahasan yang dilakukan, maka dapat disimpulkan sebagai berikut:
1. Kekuatan tarik tertinggi adalah pada komposit orientasi serat searah dengan (perendaman serat dengan $\mathrm{NaOH} 5 \%$ ) yaitu sebesar, kekuatan lentur tertinggi pada komposit orientasi serat searah dengan (perendaman serat dengan $\mathrm{NaOH}$ $7 \%$ ) yaitu sebesar UFS $=32,1 \mathrm{MPa}$, dan kekuatan impak tertinggi adalah pada komposit orientasi serat searah dengan (perendaman serat dengan $\mathrm{NaOH} 3 \%$ ) yaitu sebesar $=5468,3 \mathrm{~J} / \mathrm{m}^{2}$

2. Perendaman dengan menggunakan $\mathrm{NaOH}$ dapat meningkatkan sifat mekanik komposit karena $\mathrm{NaOH}$ dapat melarutkan lapisan lignin, hemiselulosa dan kotoran lainnya sehingga ikatan serat dan matriks menjadi lebih kuat.

3. Pemakaian serat searah dapat meningkatkan sifat mekanik komposit karena perletakan serat yang searah di dalam komposit membuat orientasi serat dalam komposit teratur dan dapat menyalurkan pembebanan atau tegangan dari satu titik ke titik lainnya sehingga ketika komposit diberikan gaya maka matriks akan dapat menahan gaya tersebut dan diteruskan oleh serat sebelum akhirnya komposit tersebut akan putus/patah.

\section{SARAN}

Untuk peneliti selanjutnya apabila menggunakan bahan yang sama dengan penelitian ini, Untuk hasil yang lebih baik hendak nya:

1. Memperhatikan saat pesngadukan atau pencampuran agar campuran benar benar homogen.

2. Memperhatikan lama waktu dan suhu ketika di hot-press agar sampel tidak terlalu keras sehingga memudahkan dalam mengeluarkan sampel dari cetakan.

3. Proses penekanan pada saat pencetakan harus dilakukan secara merata agar cetakan terisi dengan resin secara menyeluruh untuk mengurangi terjadinya void.

\section{DAFTAR PUSTAKA}


Dian, Cipta. (2010). Pengaruh Serat Gelas Model Acak dan Teratur Terhadap Sifat Mekanik Komposit Serat Ampas Tebu. Skripsi

FMIPA,Unimed, Medan.

Diharjo, K. (2008). Pengaruh Perlakuan Alkali terhadap Sifat Tarik Bahan Komposit Serat Rami-Polyester., Jurnal Teknik MesinFT UNSM, Vol.6, No.1. 